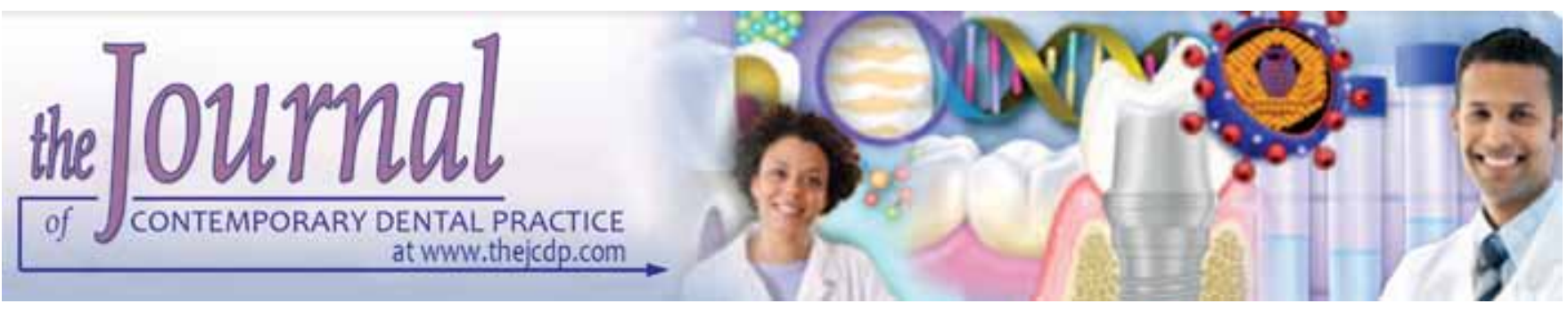

\title{
Evaluation of Effectiveness of Chemical Disinfectants in Reducing Bacterial Growth on Orthodontic Instruments
}

R Vamshidhar Reddy, K Tanveer, K Dinesh Sharma, Naveen Kokkula, PL Suresh, Meher Sudhakar

\begin{abstract}
Infection control requires serious effort in all fields of dentistry including orthodontics. Though there are various means of sterilization and disinfection in dental office, chemical disinfection is the most preferred method among orthodontists. The purpose of this study is to evaluate different chemical sterilization and disinfection methods used in orthodontic offices, which would guide the orthodontists in infection control.
\end{abstract}

Keywords: Disinfection, Sterilization, Infection control.

How to cite this article: Reddy RV, Tanveer K, Sharma KD, Kokkula N, Suresh PL, Sudhakar M. Evaluation of Effectiveness of Chemical Disinfectants in Reducing Bacterial Growth on Orthodontic Instruments. J Contemp Dent Pract 2013;14(6): 1039-1043.

\section{Source of support: Nil}

Conflict of interest: None

\section{INTRODUCTION}

Today's orthodontist has an increased awareness about spread of infection and compliance with infection control procedures. The presence of transmissible diseases like HIV/ AIDS and hepatitis B and C make it an absolute necessity to protect clinic staff and patients from cross contamination by using disinfection and sterilization techniques. ${ }^{1}$ The most commonly used methods of infection control in orthodontic offices are: steam autoclaving, dry heat oven, exposure to gaseous agents and immersion disinfection with chemical agents.

Sterilization of orthodontic instruments is a challenge because of the hinge joints and cutting edges that are difficult to clean and sterilize. However, various surveys have shown that chemical disinfection remains the most preferred mode of disinfection among orthodontists ${ }^{2,3}$ due to the disadvantages encountered with the other agents like corrosion of plier joints and other instruments, Long exposure and cooling time and cost factor.
Therefore, orthodontists should strive to provide treatment with inexpensive, yet safe infection control procedures. Chemical disinfection and sterilization would provide us both the benefits, when used with discretion.

This study was therefore conducted:

1. To study the qualitative and quantitative differences in the microbial flora cultured from two different instruments (Howe's plier and periodontal sickle scaler) after their use in the patients mouth.

2. To evaluate the effectiveness of different chemical sterilization and disinfection methods, most commonly used by orthodontists in their office, in inhibiting the growth of these organisms.

3. To provide information to orthodontic office personnel and this would serve as a reasonable guideline in selecting and using different chemical disinfection and sterilization procedures.

\section{MATERIALS AND METHODS}

\section{Predisinfection Samples}

Using sterile technique the cotton swabs were moistened in a sterile nutrient broth tube and rubbed over working end of two types of instruments-one, a serrated tip straight Howe's plier and the other, a periodontal scaler (Figs 1 and 2). The swab was then placed back in the tube labeled and racked. Ten such samples were taken per instrument at different periods of time after using in different patients.

\section{Postdisinfection Samples}

The instruments were disinfected in the following manner and sampled in the same way as described above.

\section{Disinfection with Alcohol}

Both the instruments were wiped with $70 \%$ isopropyl alcohol on sterile $2^{\prime \prime} \times 2^{\prime \prime}$ gauze squares as the only means of disinfection. 


\begin{tabular}{|c|c|c|c|}
\hline & \multicolumn{3}{|c|}{$\begin{array}{l}\text { Table 1: Significance of statis } \\
\begin{array}{l}\text { Chlorhexidine and } \\
\text { cetrimide }\end{array}\end{array}$} \\
\hline$\chi^{2}$ value & 5.5 & \multicolumn{2}{|c|}{10.71} \\
\hline$p$-value & $<0.05$ & \multicolumn{2}{|l|}{$<0.01$} \\
\hline Result & Significant & \multicolumn{2}{|c|}{ Significant } \\
\hline \multicolumn{4}{|c|}{$\begin{array}{l}\text { Table 2: Statistical comparison of the disinfectants } \\
\text { Chlorhexidine Glutaraldehyde Formaldehyde Leversept } \\
\text { and cetrimide }\end{array}$} \\
\hline 1.6 & 2.7 & $4.5^{*}$ & $4.5^{*}$ \\
\hline $\begin{array}{l}\text { Chlorhexidine + } \\
\text { cetrimide }\end{array}$ & $2.2 \mathrm{GLU}$ & 3.0 & $3.7^{*}$ \\
\hline Glutaraldehyde & & 1.0 & 1.0 \\
\hline Formaldehyde & & & 0.7 \\
\hline
\end{tabular}

*Significant at $p \leq 0.05$

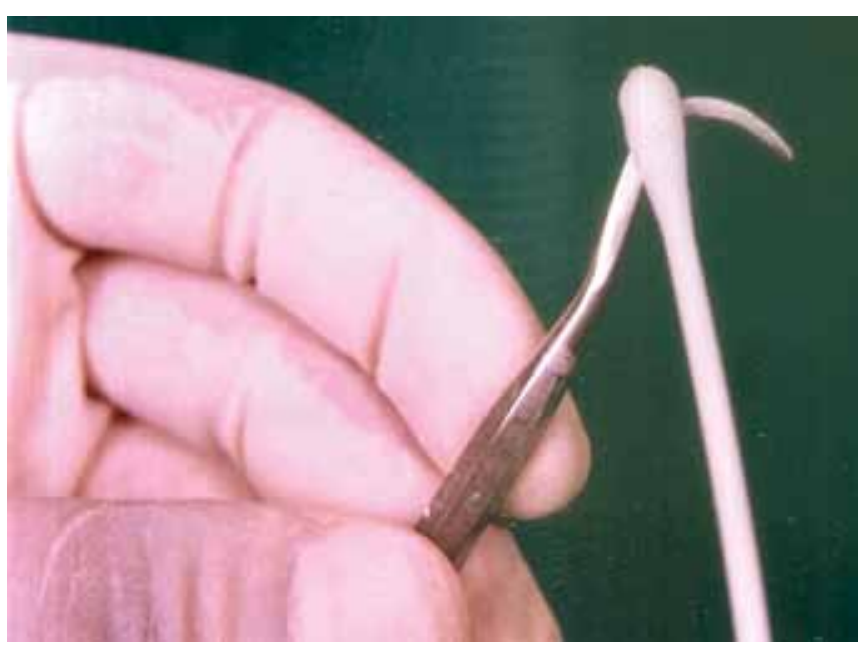

Fig. 1: Obtaining post-disinfection sample with a cotton swab

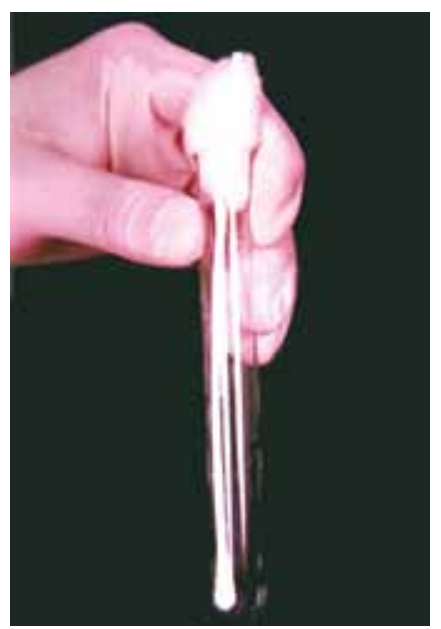

Fig. 2: Swab placed in test-tube containing broth and labelled

Before placement of the instruments for disinfection with the rest of the following agents, instruments were scrubbed in liquid detergent and rinsed in tap water.

\section{Disinfection with Chlorhexidine and Phenol}

The instruments were placed in cetrimide for 25 minutes.

\section{Disinfection with Glutaraldehyde}

Both the instruments were placed in $2 \%$ glutaraldehyde solution for 10 minutes.

\section{Disinfection with Leversept Gluteraldehyde and Formaldehyde}

Both the instruments were placed in solution of Leversept for 15 minutes.

\section{Disinfection with Formaldehyde}

Both the instruments are rescrubbed in a liquid detergent and tap water solution, rinsed under tap water, blotted dry and placed in a formaldehyde vapor chamber for 30 minutes. Swabs were taken from the instruments and sent to the laboratory.

\section{LABORATORY PROCEDURES}

The bacteria were cultured in Petri dishes containing three different culture media-MaConkey's Agar, Blood Agar and nutrient Agar(Fig. 3). The plates were incubated at $37^{\circ} \mathrm{C}$ for 24 hours. All organisms were then identified using standard procedures (Figs 4 and 5).

\section{RESULTS}

As shown in Tables 1 and 2, statistical values for comparison of effectiveness of the disinfectants used in this study showed that alcohol proved to be an inferior disinfectant when compared toglutaraldehyde, formaldehyde and leversept. There was no statistical difference in the effectiveness of other disinfectants, when compared with each other. This is in agreement with Matlack's finding that QACs compared favorably with glutaraldehyde and formaldehyde. However, it contradicts findings by Lyons, Lynch and a study conducted by Department of US Army which concluded that QACs do not compare favorably with glutaraldehyde.

\section{DISCUSSION}

Infection can directly be transmitted by oral fluids, blood, contaminated instruments or through respiration. ${ }^{1,4}$ Though orthodontists are not involved in surgeries, they come in direct contact with blood and oral fluids when placing or removing fixed appliances, ${ }^{4}$ which makes disinfection 


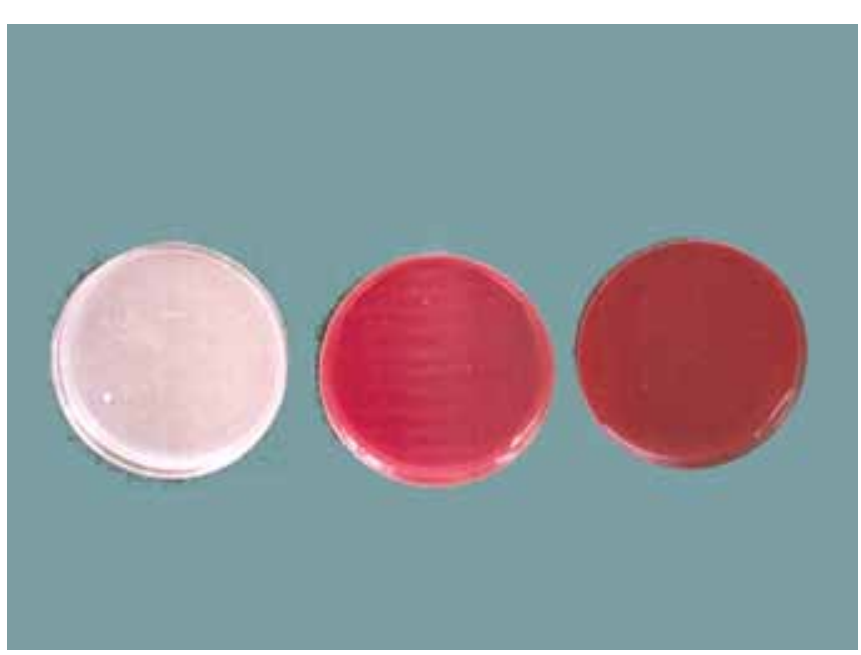

Fig. 3: The three media used for culture of bacteria nutrient agar, maconikey and blood agar

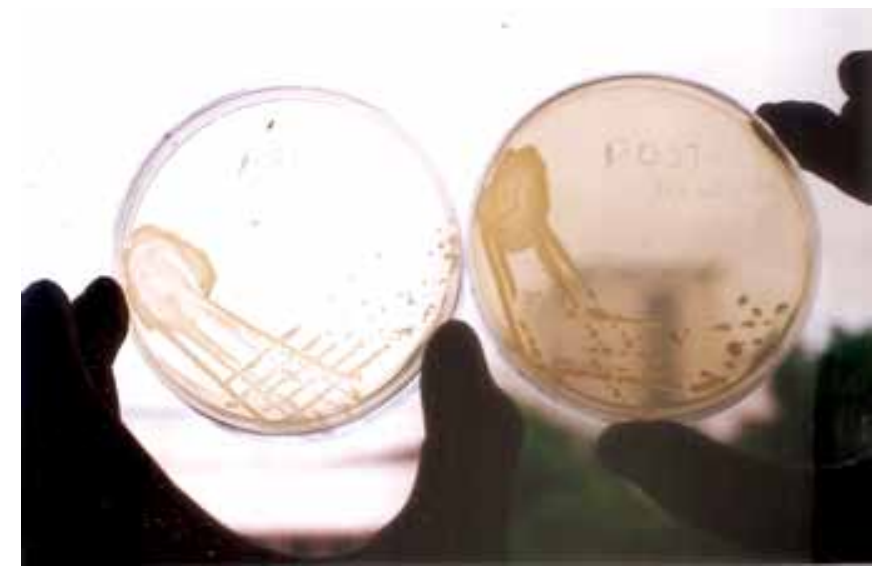

Fig. 4: Bacterial growth on nutrient agar plates after innoculation (disinfectant-alcohol)

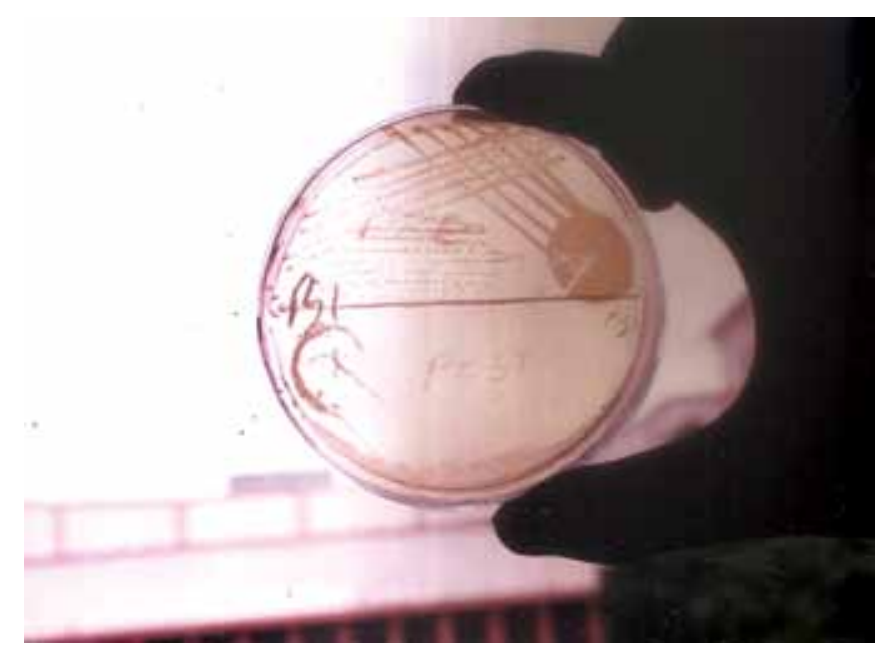

Fig. 5: Difference in bacterial growth, pre- and post-disinfection with glutaraldehyde (on single plate)

and sterilization important in orthodontic offices. It is our responsibility to apply the recent techniques in infection control to achieve the best results. ${ }^{5}$ The method of disinfection of instruments is selected according to the level of risk of infection, for example, disinfection of orthodontic pliers with $2 \%$ glutaraldehyde is the efficient method. ${ }^{6}$
A classification of chemical sterilants and disinfection was proposed by Spaulding. Three classes of disinfectants based on their efficacy against vegetative bacteria, tubercle bacilli, fungus, spores, viruses and endospores.

1. High level disinfectants: ethylene-oxide gas and glutaraldehyde. These kill bacterial spores.

2. Intermediate level disinfectants: Formaldehyde, chlorine compounds, iodophors, alcohols and phenol compounds. These destroy M. tuberculosis but may not be active against spores. They also might not be able to inactivate small nonlipid viruses which are more resistant than medium-sized lipid coated viruses.

3. Low level disinfectants: QACs (Quaternary ammonium compounds), Phenols and detergents suitable for cleaning environmental surfaces.

\section{SURVEYS OF INFECTION CONTROL IN ORTHODONTIC OFFICES}

Robert Matlack $(1979)^{7}$ conducted a survey of 50 orthodontic offices in Santa Clara Valley (December 1977).

He documented the following:

1. All use cold disinfectant solutions to some extent.

2. 47 of 50 relies totally on cold disinfectant solutions for disinfection.

3. Two use cold disinfectant solutions but use only alcohol to wipe pliers between patients.

4. One office uses a steam autoclave but for surgical instruments only.

5. Only one office used cidex 7 , a $2 \%$ buffered glutaraldehyde solution.

Robert cash $(1990)^{8}$ reported that orthodontists in Georgia have dramatically changed their sterilization and disinfection procedures. The major changes represented are greater use of protective barrier wear by doctors and staff members and increased heat sterilization methods for instruments, pliers and hand pieces; and increased disinfection of alginate impressions. Yet, when pliers were considered separately, cold sterilization and disinfection remained the first choice.

Even though research has shown the deficiencies of QAC's, Perkulis et al and Malveaux et al in their studies found them effective. ${ }^{9,10}$ Lyons, ${ }^{11}$ however, found various problems in preparation and using QAC's. In addition, American Association of Dental Schools did not accept chemical agents in preventing the transmission of infectious diseases.

\section{A NEW COMBINATION OF DISINFECTANT: LEVERSEPT ${ }^{\circledR}$}

This product uses a combination of chemicals to reap the benefits of their synergistic action and at the same time reducing the toxicity and carcinogenicity by keeping the concentrations of formaldehyde and glutaraldehyde at the 
minimum required levels. This product has been marketed internationally as Polysan and in India in being marketed since 1995 as Leversept ${ }^{\circledR}$.

\begin{tabular}{ll} 
Active ingredients & \\
\hline Benzalkonium chloride & $6.60 \% \mathrm{w} / \mathrm{w}$ \\
Formaldehyde & $5.00 \% \mathrm{w} / \mathrm{w}$ \\
Glutaraldehyde & $3.40 \% \mathrm{w} / \mathrm{w}$ \\
Ethane dialdehyde & $8.40 \% \mathrm{w} / \mathrm{w}$ \\
Nonionic surfactants & qs \\
\hline
\end{tabular}

\section{COMPARATIVE EVALUATION OF DISINFECTANT PROPERTIES OF THE CHEMICAL AGENTS USED}

As shown in Table 2, statistical values for comparison of effectiveness of the disinfectants used in this study showed that alcohol proved to be an inferior disinfectant when compared to glutaraldehyde, formaldehyde and leversept. There was no statistical difference in the effectiveness of other disinfectants, when compared with each other. This is in agreement with Matlack's finding that QACs compared favorably with glutaraldehyde and formaldehyde. However, it contradicts findings by Lyons, Lynch and a study conducted by Department of US. Army which concluded that QACs do not compare favorably with glutaraldehyde. This difference in findings may be due to variance in disinfection procedures like:

1. Use of hard water or soap for predisinfection cleaning which decreases effectiveness of QACs.

2. Difference in washing procedures after disinfection. Washing with soap would reduce the residual action of QACs.

3. Contamination of instruments by environmental bacteria after disinfection.

\section{SUMMARY AND CONCLUSION}

This study was undertaken to evaluate the level of disinfection of hand instruments using five different chemical agents - alcohols, chlorhexidine and cetrimide, glutaraldehyde, formaldehyde and leversept.

The salient points of conclusion derived from this study are:

1. The most commonly found bacteria on the instruments were streptococci, staphylococci, E.coli.

2. The effectiveness of the disinfectants studied, in the order of increasing effectiveness is: (1) alcohol,

(2) chlorhexidine and cetrimide, (3) glutaraldehyde,

(4) formaldehyde, (5) Leversept (Graph 1).

3. With respect of QACs the findings of Matlack have been validated. This study concluded that QACs compared favorably with glutaraldehyde.

4. Even with glutaraldehyde, formaldehyde chamber and leversept, it was shown that only a high level disin-

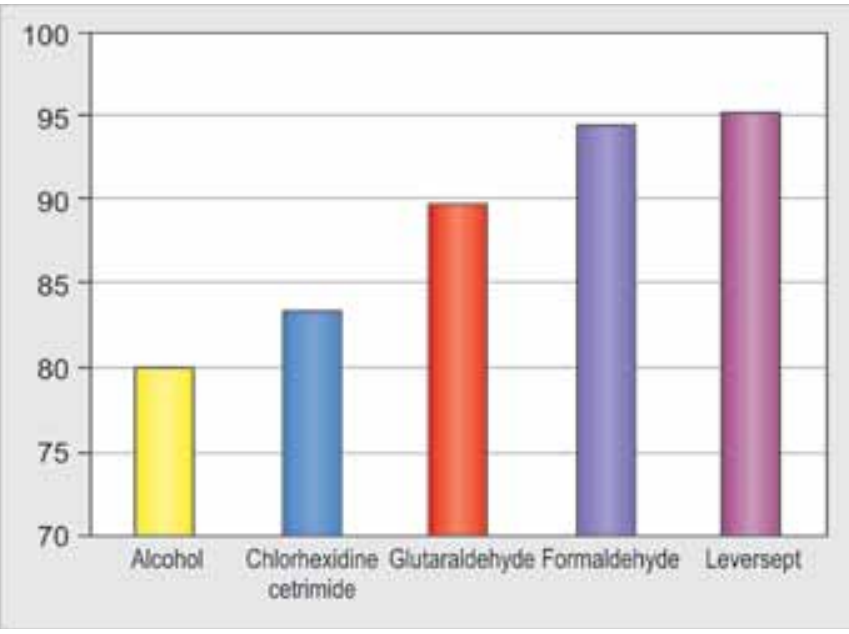

Graph 1: Percentage reduction of overall bacterial growth using different disinfectants

fection was obtained by using cycles below 30 minutes. Therefore one should increase the time period for situations where complete sterilization is required. For these agents, 10 hours exposure would ensure complete sterility.

5. This study has discussed the evolution of newer disinfection agents which aim at eliminating the toxic and allergic effects of the chemicals by combining them with safer disinfectants like benzalkonium chloride (a QAC), to produce nonirritating, nontoxic disinfectants. The efficacy of one such disinfectant Leversept has been demonstrated. As it also contains anticorrosive agents, it is ideally suited for orthodontic use.

\section{REFERENCES}

1. Shah R, Collins M, Hodge TM, Laing ER. A national study of cross infection control: 'are we clean enough? British Dental Journal 2009;207:267-274.

2. Buckthal JE. Survey of sterilization and disinfection procedures: JCO 1986 Nov;759-765.

3. Woo J, Anderson R, Maguire B, Gerbert B. Compliance with Infection Control Procedures among California Orthodontists. AJO-DFD 1992;102:68-75.

4. Toroglu SM, Haytac C, Koksal F. Evaluation of aerosol contamination during debonding procedures. Angle Orthodontist 2001;71:299-306.

5. Hayder SG. Orthodontic sterilization vs disinfection TDBD 2000;58.

6. de Almeida CMF, de Carvalho AS, Duarte DA. Evaluation of disinfection methods of orthodontic Pliers. Dental press J Orthod 2012 Jul-Aug;17(4):105-109.

7. Matlack RE. Instrument sterilization in orthodontic offices. Angle Orthod 1979 July;49(3):205-211.

8. Cash RG. Trends in Sterilization and disinfection procedures. Am J Orthod Dentofacial Orthop 1990 Oct;292-299.

9. Perkulis B, Warren E, Kramer WS. Ultrasonics and Benzalkonium Chloride as a method of sterilizing dental instuments. J Dent Children 1970;37:69-78. 
10. Malveaux FJ, Whitehurst VE, Magerman LA. Relative effectiveness of certain chemosterilizers on selected microbial species. J Dental Resear 1972 Jan;51(1):62-66.

11. Lyon TC. Quaternary Ammonia Compounds: Should they be used for disinfection in dental office. J DC Dental Society 1973;10-18.

\section{ABOUT THE AUTHORS}

\section{R Vamshidhar Reddy}

Professor and Head, Department of Ortho and DFO, HSRSM Dental College, Hingoli, Maharashtra, India

\section{K Tanveer}

Reader, Department of Oral and Maxillofacial Surgery, SB Patil Dental College and Hospital, Bidar, Karnataka, India

\section{K Dinesh Sharma}

Dean, Professor and Head, Department of Oral and Maxillofacial Surgery, SB Patil Dental College and Hospital, Bidar, Karnataka, India

\section{Naveen Kokkula}

Reader, Department of Oral and Maxillofacial Surgery, Aditya Dental College, Beed, Maharashtra, India

\section{PL Suresh}

Assistant Professor, Department of Oral and Maxillofacial Surgery SB Patil Dental College and Hospital, Bidar, Karnataka, India

\section{Meher Sudhakar}

Senior Lecturer, Department of Oral and Maxillofacial Surgery, Srisai College of Dental Sciences, Vikarabad, Andhra Pradesh, India 